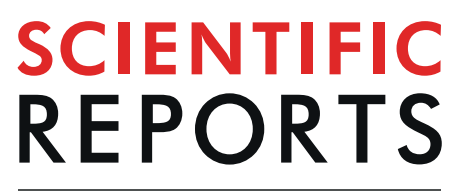

natureresearch

\title{
Relationships of diabetes and hyperglycaemia with intraocular pressure in a Japanese population: the JPHC-NEXT Eye Study
}

\author{
Akiko Hanyuda ${ }^{1,2}$, Norie Sawada $\mathbb{D}^{2 *}$, Kenya Yuki $\mathbb{D}^{1 *}$, Miki Uchino ${ }^{1}$, Yoko Ozawa $\mathbb{1}^{1}$, \\ Mariko Sasaki $\mathbb{C}^{1,3,4}$, Kazumasa Yamagishi $\mathbb{D}^{5,6}$, Hiroyasu 1 so $^{7}$, Kazuo Tsubota $\mathbb{D}^{1}$ \& \\ Shoichiro Tsugane $\mathbb{B}^{2}$
}

Although a meta-analysis previously suggested a positive relationship between diabetes and intraocular pressure (IOP), the interrelationships among diabetes, IOP, and other ocular biometric parameters remain unclear. The present study investigated the relationships of diabetes, haemoglobin A1c (HbA1c), and serum glucose with IOP and ocular hypertension (IOP $>21 \mathrm{mmHg}$ ) in non-glaucomatous Japanese adults living in Chikusei City. Diabetes was defined as a self-reported history of diabetes, the use of antidiabetic medication, or HbA1c levels $\geq 6.5 \%$. Among 6,786 enrolled participants aged 40 years and above, 734 were classified as diabetic (10.8\%). After adjusting for several confounders, the IOP values were significantly higher in participants with diabetes than in those without diabetes $(14.4 \pm 0.1$ vs. $13.9 \pm 0.1 \mathrm{mmHg}, \mathrm{P}<0.001$ ) and were also significantly increased in those with elevated $\mathrm{HbAlc}$ and serum glucose levels (both $\mathrm{P}<0.001$ ). Moreover, diabetes was significantly related to ocular hypertension (multivariable-adjusted odds ratio, $1.75 ; 95 \%$ confidence interval, $1.09-2.81 ; \mathrm{P}<0.05$ ). The positive influence of diabetes with ocular hypertension was consistent even after adjustment for central corneal thickness. In conclusion, diabetes, elevated HbAlc, and increased serum glucose are significant contributing factors for elevated IOP.

Over the past several decades, the prevalence of type 2 diabetes has increased markedly in Asian countries ${ }^{1}$, and patients with diabetes in these countries currently account for more than $60 \%$ of the global diabetic population $^{2}$. Partly due to a marked change in dietary habits and lifestyle in Asia, type 2 diabetes has become a major public health burden, leading to substantial financial loss due to increased morbidity, mortality, and health care expenditures ${ }^{3}$. Diabetes is commonly accompanied by microvascular damage, which might contribute to numerous ocular complications, including elevated intraocular pressure (IOP) $)^{4-6}$ and subsequent glaucoma ${ }^{4,7-10}$, a leading cause of irreversible blindness worldwide ${ }^{11}$. According to a recent meta-analysis of 47 studies from 16 countries $^{9}$, a history of diabetes was associated with an average increase of $0.18 \mathrm{mmHg}$ (95\% confidence interval [CI], 0.09-0.27) in IOP and a 48\% increased relative risk for primary open-angle glaucoma (POAG) compared to the risk in nondiabetic patients.

The underlying mechanisms linking diabetes and elevated IOP have not been fully elucidated. Accumulating evidence suggests that a hyperglycaemic status may disrupt cell and repair functions in the cornea ${ }^{12-15}$, thus potentially affecting the central corneal thickness $(\mathrm{CCT})^{16,17}$. Because IOP values rise by $0.11-1.00 \mathrm{mmHg}$ per $10-\mu \mathrm{m}$ increase in $\mathrm{CCT}^{18-20}$, it is plausible that a positive association between diabetes and high IOP may be partly

${ }^{1}$ Department of Ophthalmology, Keio University School of Medicine, 35 Shinanomachi, Shinjuku-ku, Tokyo, 160-8582, Japan. ${ }^{2}$ Epidemiology and Prevention Group, Centre for Public Health Sciences, National Cancer Centre, 51-1 Tsukiji, Chuo-ku, Tokyo, 104-0045, Japan. ${ }^{3}$ Tachikawa Hospital, 4-2-22 Nishiki-cho, Tachikawa, Tokyo, 190-8531, Japan. ${ }^{4}$ National Institute of Sensory Organs, National Tokyo Medical Centre, 2-5-1 Higashigaoka, Meguro-ku, Tokyo, 152-8902, Japan. ${ }^{5}$ Department of Public Health Medicine, Faculty of Medicine, and Health Services Research and Development Centre, University of Tsukuba, 1-1-1 Tennodai, Tsukuba, Ibaraki, 305-8575, Japan. ${ }^{6}$ Ibaraki Western Medical Centre, 555 Otsuka, Chikusei, Ibaraki, 308-0813, Japan. ${ }^{7}$ Department of Social and Environmental Medicine, Osaka University Graduate School of Medicine, 2-2Yamadaoka, Suita, Osaka, 565-0871, Japan. *email: nsawada@ ncc.go.jp; yukikenya114@gmail.com 
attributable to a greater CCT in patients with diabetes. Nevertheless, many previous studies that examined the association between diabetes and IOP did not consider CCT measurements ${ }^{7,21-24}$, despite it being a plausible IOP regulating factor ${ }^{18-20}$.

Considerable evidence suggests that systemic and ocular biometric parameters are affected by genetic and environmental factors ${ }^{9,25-27}$. However, population-based studies of such factors in Asians are limited ${ }^{27-29}$. Specifically, in terms of IOP, Japanese adults may have unique characteristics compared to other populations: a relatively low $\mathrm{IOP}^{29-31}$ and a significant prevalence of normal-tension glaucoma $(3.3-3.6 \%)^{32,33}$. The mean IOP in non-glaucomatous Japanese individuals $(11.8-14.5 \mathrm{mmHg})^{29-31}$ was lower than that in Caucasians $(17.2 \mathrm{mmHg})^{34}$ and other Asians, including Malays $(15.3 \mathrm{mmHg})^{35}$ and Indians $(15.8 \mathrm{mmHg})^{35}$. Since the suggested positive relationship between diabetes and IOP was largely based on research conducted in Western countries ${ }^{9}$, this relationship should be re-examined in East Asian populations. Furthermore, it is not clear whether diabetes is a CCT-independent cause of elevated IOPs or whether the observed positive association between diabetes and IOP is merely mediated by CCT increases. To the best of our knowledge, no study has investigated the interrelationships among diabetes, IOP, and CCT in a Japanese population.

Here, the influence of type 2 diabetes, serum glucose, and haemoglobin A1c (HbAlc, which is considered to reflect the average serum glucose level in the previous 2-3 months) levels on IOP was evaluated using a large body of data from ophthalmologically normal Japanese adults who participated in an epidemiological survey conducted in Chikusei City, Japan.

\section{Results}

Characteristics of systemic and ocular factors in participants with and without diabetes. Among the 6,786 enrolled participants (4,013 men and 2,773 women), 734 (10.8\%; 292 men and 442 women) had diabetes. The mean age \pm standard deviation (SD) was slightly higher in patients with diabetes $(66.9 \pm 7.8$ years) than in participants without diabetes $(63.3 \pm 10.0$ years, $\mathrm{P}<0.001$; Table 1$)$. Individuals with diabetes were more likely to have a history of smoking; higher body mass index (BMI) and waist circumference; higher levels of HbA1c, non-fasting serum glucose, triglycerides, and IOP; and lower high-density lipoprotein cholesterol levels (Table 1). Figure 1 shows the IOP distribution according to the diabetic status. The mean IOP $\pm S D$ was $14.3 \pm 2.8 \mathrm{mmHg}$ for participants with diabetes and $13.9 \pm 2.8 \mathrm{mmHg}$ for those without diabetes $(\mathrm{P}<0.001)$. The demographic breakdown of the IOP data from the participants in this study is presented in Supplementary Table S1. The mean IOP \pm SD was $13.7 \pm 2.8 \mathrm{mmHg}$ in men and $14.1 \pm 2.8 \mathrm{mmHg}$ in women, and the IOP values were inversely correlated with age in both sexes.

Relationships of diabetes, haemoglobin A1c, and serum glucose with intraocular pressure. After adjusting for age, sex, and several lifestyle and metabolic factors, diabetes was significantly related to higher IOP values (mean IOP $[ \pm$ standard error, SE] in patients with diabetes vs. participants without diabetes: $14.4 \pm 0.1$ vs. $13.9 \pm 0.1 \mathrm{mmHg}$, respectively, $\mathrm{P}<0.001$; Table 2). Similarly, individuals with higher serum $\mathrm{HbA1c}$ or serum glucose levels had elevated IOPs $(\mathrm{P}<0.001)$. We confirmed these relationships after controlling for waist circumference, a good proxy for adiposity traits, instead of adjusting for BMI (data not shown), as well as in subgroup analyses by sex (data not shown). Additionally, we further adjusted the relationships for CCT and confirmed that the identified positive relationships of diabetes, serum $\mathrm{HbAlc}$, and serum glucose with IOP were generally consistent.

Relationships of diabetes, haemoglobin A1c, and serum glucose with ocular hypertension. Multivariable-adjusted logistic regression analyses showed that individuals with diabetes had an approximately two-fold higher prevalence of ocular hypertension than those without diabetes (multivariable-adjusted odds ratio [OR], 1.75; 95\% CI, 1.09-2.81; $\mathrm{P}<0.05$; Table 3). Likewise, higher serum HbA1c $(\geq 6.0 \%)$ and higher serum glucose (fasting $\geq 110$ or non-fasting $\geq 140 \mathrm{mg} / \mathrm{dL}$ ) levels were significantly related to ocular hypertension (multivariable-adjusted OR [95\% CI] for HbA1c $\geq 6.0 \%$ vs. $<6.0 \%$ : 1.47 [1.00-2.17], P $<0.05$; for serum glucose with fasting levels $\geq 110$ or non-fasting levels $\geq 140 \mathrm{mg} / \mathrm{dL}$ vs. fasting levels $<110$ or non-fasting levels $<140 \mathrm{mg} /$ $\mathrm{dL}: 1.80$ [1.11-2.92], P $<0.05)$. Similar relationships were evident after controlling for CCT.

\section{Discussion}

This large Japanese population-based study assessed the relationships of diabetes, HbA1c, and serum glucose with IOP in non-glaucomatous individuals. After controlling for several possible confounders, the current study suggested that individuals with diabetes had significantly higher IOP than those without diabetes. Furthermore, patients with diabetes had an $80 \%$ increased prevalence of ocular hypertension compared to participants without diabetes, even after controlling for CCT measurements.

Consistent with a recent systematic review and meta-analysis ${ }^{9}$, the present results showed that a history of diabetes was related to both increased IOP and the presence of ocular hypertension. Earlier self-reported questionnaire-based studies showed a non-significant association between diabetes and high IOP ${ }^{36-39}$. In the present study, the positive relationship between poor glycaemic control, characterized by increased $\mathrm{HbAlc}$ or serum glucose levels, and high IOP was reaffirmed, in addition to the use of a questionnaire-based definition.

Accumulating evidence from epidemiological and animal studies suggests a causal link between hyperglycaemic status and increased IOP ${ }^{4,6,8,40,41}$; however, less is known about how excessive plasma glucose can elevate ocular tension in the anterior chamber. One conceivable explanation may involve the elevation of transforming growth factor (TGF)- 32 levels in the context of diabetes and the subsequent dysfunction of the trabecular meshwork, which reduces the outflow of the aqueous humour and elevates the IOP ${ }^{41}$. TGF- $\beta$ may inhibit the proliferation and migration of trabecular cells ${ }^{42-44}$. Ochiai et al. ${ }^{45}$ and Min et al. ${ }^{46}$ reported increased levels of TGF- $\beta 2$ in the aqueous humour and trabecular meshwork of eyes in individuals with diabetes. At least in mouse 


\begin{tabular}{|c|c|c|c|}
\hline Characteristics & $\begin{array}{l}\text { Diabetes }^{\ddagger} \\
(\mathrm{n}=734)\end{array}$ & $\begin{array}{l}\text { No diabetes } \\
(\mathrm{n}=6,052)\end{array}$ & P-value \\
\hline \multicolumn{4}{|l|}{ Demographic features } \\
\hline Mean age in years $(\mathrm{SD})^{\mathrm{b}}$ & $66.9(7.8)$ & $63.3(10.0)$ & $<0.001$ \\
\hline Male participants, n (\%) & $292(39.8)$ & $3,721(61.5)$ & $<0.001$ \\
\hline Body mass index, $\mathrm{kg} / \mathrm{m}^{2}(\mathrm{SD})$ & $24.6(3.8)$ & $23.0(3.2)$ & $<0.001$ \\
\hline Waist circumference, $\mathrm{cm}$ (SD) & $78.1(28.6)$ & $74.2(25.9)$ & $<0.001$ \\
\hline Weight, kg (SD) & $64.6(13.1)$ & $57.0(10.4)$ & $<0.001$ \\
\hline Height, cm (SD) & $158.6(10.3)$ & $157.0(10.1)$ & $<0.001$ \\
\hline Smoking status, n (\%) & & & $<0.001$ \\
\hline Never smokers & 36.5 & 24.2 & \\
\hline Current smokers & 16.3 & 12.6 & \\
\hline Alcohol intake, n (\%) & & & 0.01 \\
\hline$<23$ g/day & 56.0 & 58.3 & \\
\hline 23 to $<46$ g/day & 14.0 & 16.4 & \\
\hline$\geq 46 \mathrm{~g} /$ day & 30.0 & 25.2 & \\
\hline \multicolumn{4}{|l|}{ Systemic features } \\
\hline Hypertension, n (\%) & 57.2 & 44.9 & $<0.001$ \\
\hline Systolic blood pressure, $\mathrm{mmHg}(\mathrm{SD})$ & $130.3(17.1)$ & $125.1(17.6)$ & $<0.001$ \\
\hline Diastolic blood pressure, $\mathrm{mmHg}(\mathrm{SD})$ & $75.3(11.1)$ & $74.6(11.6)$ & 0.06 \\
\hline HDL cholesterol, mg/dL (SD) & $56.4(14.2)$ & $64.0(15.8)$ & $<0.001$ \\
\hline LDL cholesterol, mg/dL (SD) & $120.3(32.6)$ & $125.9(31.1)$ & $<0.001$ \\
\hline Triglyceride, mg/dL $(\mathrm{SD})^{\mathrm{c}}$ & $115.0(77.9)$ & $95.0(68.5)$ & $<0.001$ \\
\hline $\mathrm{HbAlc}, \%(\mathrm{SD})^{\mathrm{c}}$ & $6.7(1.2)$ & $5.6(0.3)$ & $<0.001$ \\
\hline Participants with fasting glucose levels, n (\%) & $452(61.6)$ & $3,991(66.0)$ & 0.02 \\
\hline Fasting glucose, $\mathrm{mg} / \mathrm{dL}(\mathrm{SD})^{\mathrm{d}}$ & $132.4(33.3)$ & $96.3(9.5)$ & $<0.001$ \\
\hline Non-fasting glucose, mg/dL (SD) ${ }^{\mathrm{d}}$ & $138.2(45.6)$ & $97.6(13.1)$ & $<0.001$ \\
\hline \multicolumn{4}{|l|}{ Ocular features } \\
\hline Central corneal thickness, $\mu \mathrm{m}(\mathrm{SD})$ & $554.3(49.2)$ & $550.0(59.3)$ & 0.16 \\
\hline Intraocular pressure, $\mathrm{mmHg}(\mathrm{SD})$ & $14.3(2.8)$ & $13.9(2.8)$ & $<0.001$ \\
\hline Ocular hypertension, $\mathrm{n}(\%)$ & $24(3.1)$ & $111(1.9)$ & 0.01 \\
\hline
\end{tabular}

Table 1. Demographic, systemic, and ocular characteristics of the participants according to their diabetic status ${ }^{a}{ }^{a}$ Values are presented as the means (SDs) for continuous variables and percentages for categorical variables. ${ }^{b}$ Diabetes was defined as self-reported antidiabetic medication use, physician-diagnosed diabetes, or $\mathrm{HbAlc} \geq 6.5 \%$. ${ }^{\mathrm{b}}$ All values other than age were adjusted for age and sex. ${ }^{\mathrm{c}}$ For triglycerides and HbAlc, medians (SDs) are presented. dSerum glucose levels were examined in 2013-2016. HbAlc, haemoglobin A1c; HDL, high-density lipoprotein; LDL, low-density lipoprotein; SD, standard deviation.

studies, human TGF- $\beta 2$ decreased the aqueous outflow and increased the $\mathrm{IOP}^{41}$. Although future studies are warranted, high concentrations of TGF- $\beta 2$ in diabetes may contribute to increased outflow resistance and elevated IOP. Another publication suggests the accumulation of advanced glycation end-products (AGEs) in trabecular meshwork cells in patients with diabetes ${ }^{47}$. Since increased levels of AGEs induce oxidative stress and apoptosis in human trabecular meshwork cells ${ }^{48,49}$, the impaired trabecular meshwork functions under these conditions may lead to an increased $\mathrm{IOP}^{50}$.

The present study provides evidence that the positive relationships between hyperglycaemic status and IOP were significant, even after controlling for CCT. Increases in CCT may lead to overestimated IOP values ${ }^{35,51,52}$, and diabetic patients have relatively greater CCTs due to the osmotic gradients induced by accumulated sorbitol in the corne ${ }^{53}$. Accordingly, several studies have suggested that a greater CCT may mediate the association between higher glucose levels and elevated $\mathrm{IOP}^{10,54}$. In our current study, we tested the potential role of CCT as a mediator of diabetes and IOP. In the multiple linear regression analyses with diabetes predicting CCT (exposure-mediator) and with CCT predicting IOP (mediator-outcome), both relationships were statically significant $(\mathrm{P}<0.05)$. Besides, the diabetes-IOP relationship was also significant after CCT adjustment, suggesting CCT as a partial mediator in our study population ${ }^{55,56}$. These findings are consistent with those of a previous study from Singapore reporting that a higher IOP in patients with diabetes was not primarily mediated by a greater CCT in these patients ${ }^{10}$. Therefore, controlling blood sugar in patients with diabetes is important to reduce future glaucoma susceptibility.

Nevertheless, the link between diabetes and POAG-related traits, including IOP, remains controversial in recent findings from genome-wide association studies ${ }^{57-59}$. Although Shiga et al. found a significant positive correlation between diabetes and POAG in a Japanese population ${ }^{57}$, another Japanese genetic study ${ }^{58}$ and a study in European $s^{59}$ found no such association. Although genetic analyses are increasingly recognized as useful tools for providing unbiased estimates without confounding by reverse-causality or measurement errors, there are some non-genetic factors (i.e., impaired trabecular meshwork due to hyperglycaemia-induced inflammation or 


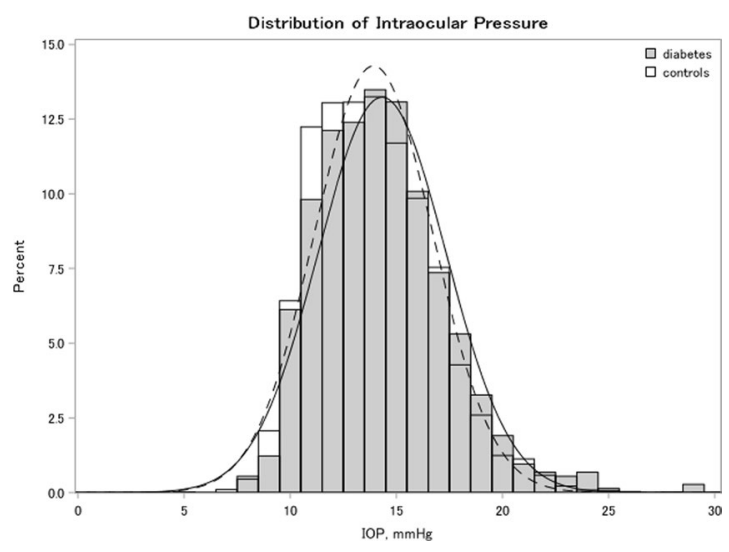

Figure 1. Intraocular pressure (IOP) distribution in the right eye of participants according to their diabetic status. The IOP distribution is indicated by white bars with a dotted line for controls and grey bars with a solid line for patients with diabetes.

\begin{tabular}{|c|c|c|c|c|c|c|c|}
\hline \multirow[b]{2}{*}{ Characteristics } & \multirow[b]{2}{*}{ No. (\%) } & \multicolumn{6}{|c|}{ Mean intraocular pressure, $\mathrm{mmHg}(\mathrm{SE})$} \\
\hline & & $\begin{array}{l}\text { Age- and sex- } \\
\text { adjusted }\end{array}$ & P-value & $\begin{array}{l}\text { Multivariable- } \\
\text { adjusted }^{\text {a }}\end{array}$ & P-value & $\begin{array}{l}\text { Multivariable- } \\
\text { adjusted }^{\text {b }}\end{array}$ & P-value \\
\hline \multicolumn{8}{|l|}{ Diabetes $^{\mathrm{c}}$} \\
\hline No & $6,052(89.2)$ & $13.9(0.1)$ & \multirow{2}{*}{$<0.001$} & $13.9(0.1)$ & \multirow{2}{*}{$<0.001$} & $13.9(0.1)$ & \multirow{2}{*}{$<0.001$} \\
\hline Yes & $734(10.8)$ & $14.5(0.1)$ & & $14.4(0.1)$ & & $14.3(0.1)$ & \\
\hline \multicolumn{8}{|l|}{ Serum HbAlc, \% } \\
\hline$<6.0 \%$ & $5,206(76.7)$ & $13.9(0.1)$ & \multirow{2}{*}{$<0.001$} & $13.9(0.1)$ & \multirow{2}{*}{$<0.001$} & $13.8(0.1)$ & \multirow{2}{*}{$<0.001$} \\
\hline$\geq 6.0 \%$ & $1,580(23.3)$ & $14.3(0.1)$ & & $14.2(0.1)$ & & $14.1(0.1)$ & \\
\hline \multicolumn{8}{|l|}{ Serum glucose, $\mathrm{mg} / \mathrm{dL}^{\mathrm{d}}$} \\
\hline $\begin{array}{l}\text { Fasting }<110 \text { or } \\
\text { non-fasting }<140\end{array}$ & $5,282(86.1)$ & $13.8(0.1)$ & \multirow{2}{*}{$<0.001$} & $13.8(0.1)$ & \multirow{2}{*}{$<0.001$} & $13.8(0.1)$ & \multirow{2}{*}{$<0.001$} \\
\hline $\begin{array}{l}\text { Fasting } \geq 110 \text { or } \\
\text { non-fasting } \geq 140\end{array}$ & $853(13.9)$ & $14.6(0.1)$ & & $14.4(0.1)$ & & $14.4(0.1)$ & \\
\hline
\end{tabular}

Table 2. Adjusted mean intraocular pressure by diabetes, HbAlc, and serum glucose. adjusted for age, sex, smoking status, alcohol intake, hypertension, and body mass index. ${ }^{\mathrm{b}}$ Adjusted for age, sex, smoking status, alcohol intake, hypertension, body mass index, and central corneal thickness. ${ }^{c}$ Diabetes was defined as selfreported antidiabetic medication use, physician-diagnosed diabetes, or HbAlc $\geq 6.5 \%$. 'Serum glucose data were only available between 2013-2016 for 6,135 samples out of 6,786 study participants in 2013-2017. HbA1c, haemoglobin A1c; SE, standard error.

\begin{tabular}{|c|c|c|c|c|}
\hline \multirow[b]{2}{*}{ Characteristics } & \multirow[b]{2}{*}{ No. (\%) } & \multicolumn{3}{|l|}{ OR $(95 \% \mathrm{CI})$} \\
\hline & & $\begin{array}{l}\text { Age- and sex- } \\
\text { adjusted }\end{array}$ & $\begin{array}{l}\text { Multivariable- } \\
\text { adjusted }^{\text {a }}\end{array}$ & $\begin{array}{l}\text { Multivariable- } \\
\text { adjusted }^{\text {b }}\end{array}$ \\
\hline \multicolumn{5}{|l|}{ Diabetes $^{c}$} \\
\hline No & $112(1.9)$ & ${ }^{1}[$ Reference $]$ & ${ }^{1}[$ Reference $]$ & ${ }^{1}[$ Reference $]$ \\
\hline Yes & $23(3.1)$ & $1.89(1.19-3.02)^{*}$ & $1.75(1.09-2.81)^{\dagger}$ & $1.92(1.13-3.28)^{\dagger}$ \\
\hline \multicolumn{5}{|l|}{ Serum HbA1c, \% } \\
\hline$<6.0 \%$ & $94(1.8)$ & ${ }^{1}[$ Reference $]$ & ${ }^{1}[$ Reference $]$ & ${ }^{1}[$ Reference $]$ \\
\hline$\geq 6.0 \%$ & $41(2.6)$ & $1.59(1.09-2.32)^{\dagger}$ & $1.47(1.00-2.17)^{\dagger}$ & $1.49(0.95-2.32)$ \\
\hline \multicolumn{5}{|l|}{ Serum glucose, $\mathrm{mg} / \mathrm{dL}^{\mathrm{d}}$} \\
\hline $\begin{array}{l}\text { Fasting }<110 \text { or } \\
\text { non-fasting }<140\end{array}$ & $81(1.5)$ & ${ }^{1}[$ Reference $]$ & ${ }^{1}[$ Reference $]$ & ${ }^{1}[$ Reference $]$ \\
\hline $\begin{array}{l}\text { Fasting } \geq 110 \text { or } \\
\text { non-fasting } \geq 140\end{array}$ & $24(2.8)$ & $1.97(1.22-3.17)^{\ddagger}$ & $1.80(1.11-2.92)^{\dagger}$ & $1.75(1.07-2.87)^{\dagger}$ \\
\hline
\end{tabular}

Table 3. Multivariable logistic regression analyses of the relationships of ocular hypertension (intraocular pressure $>21 \mathrm{mmHg}$ ) with diabetes, $\mathrm{HbAlc}$, and serum glucose. ${ }^{\mathrm{a}}$ Adjusted for age, sex, smoking status, alcohol intake, hypertension, and body mass index. ${ }^{\mathrm{b}}$ Adjusted for age, sex, smoking status, alcohol intake, hypertension, body mass index, and central corneal thickness. ${ }^{c}$ Diabetes was defined as self-reported antidiabetic medication use, physician-diagnosed diabetes, or $\mathrm{HbA1c} \geq 6.5 \%$. ${ }^{\mathrm{d}}$ Serum glucose data were only available between $2013-$ 2016 for 6,135 samples out of 6,786 study participants in 2013-2017. Test for significance: ${ }^{\dagger} \mathrm{P}<0.05,{ }^{\ddagger} \mathrm{P}<0.01$. $\mathrm{CI}$, confidence interval; HbA1c, haemoglobin A1c; OR, odds ratio. 
accumulation of AGEs) that possibly explain the link between diabetes and high IOP. Hence, additional large population-based studies examining the complex relationships among diabetes, CCT, and IOP in different ethnic groups are warranted.

This study had several limitations. First, the current findings are based on cross-sectional observations, which prevent the confirmation of causality between an increase or decrease in any of the parameters and changes in IOP. Although future longitudinal studies are warranted, studies assessing the interrelationships between diabetes and ocular biometric parameters, such as the current study, are noteworthy. Second, given that ocular hypertension is diagnosed by comprehensive ocular evaluations, including visual-field tests, the employed IOP measurement by non-contact pneumotonometry is not completely reflective of ocular hypertension. However, the mean IOP \pm SD of $14.0 \pm 2.8 \mathrm{mmHg}$ in the present study was close to that of $14.5 \mathrm{mmHg}$ in the Tajimi Study ${ }^{29}$, in which 3,021 non-glaucomatous individuals aged $>40$ years were subjected to Goldmann applanation tonometry. Furthermore, the use of Goldmann applanation tonometry may induce a larger amount of inter-investigator heterogeneity than encountered when using non-contact devices ${ }^{60}$. Generally, hospital-based studies, including detailed ocular investigations, may be hampered by selection bias and power issues. The present large population-based study reduced the effects of these caveats, although the results should still be interpreted cautiously. In addition, we did not include serum glucose levels in our definition of diabetes due to the unavailability of serum glucose levels in 2017. We acknowledge the possible underdiagnosis of diabetes and exposure misclassification. However, we conducted sensitivity analyses for the 2013-2016 participants using a diabetes definition that included serum glucose levels ( $\geq 200 \mathrm{mg} / \mathrm{dL}$ for non-fasting or $\geq 126 \mathrm{mg} / \mathrm{dL}$ for fasting serum glucose levels) and confirmed that the results were generally consistent (data not shown). Finally, the present data are restricted to a Japanese population, which might affect the generalizability. Nevertheless, the findings can be generally applied to other East Asian populations.

The strengths of our study include adequate power with substantial information on lifestyle and ocular parameters. The ophthalmic databases were rigorously evaluated by experienced ophthalmologists. In the current study, hyperglycaemic status was defined based on both self-reported questionnaires and laboratory data, including serum glucose and $\mathrm{HbAlc}$, which should be more accurate than the data obtained only by self-reported patient information.

In conclusion, we found that diabetes and hyperglycaemia were significantly related to increased IOP among ophthalmologically healthy Japanese adults. This finding underscores the importance of appropriate glycaemic control to avoid IOP-related consequences in patients with diabetes.

\section{Methods}

Study population. The Japan Public Health Centre-based Prospective Study for the Next Generation (JPHC-NEXT) Eye Study is an ancillary investigation of an ongoing population-based study conducted under the protocol of the JPHC-NEXT Study ${ }^{61}$. Between 2013 and 2017, we performed a systemic and ophthalmological survey, as well as the JPHC-NEXT baseline surveillance in Chikusei City, located in central Japan, approximately $70 \mathrm{~km}$ north of Tokyo. All participants were asked about their socio-demographics, lifestyle factors (e.g., alcohol use or smoking status), medical history (e.g., history of diabetes or hypertension), ocular history (i.e., cataract surgery and refractive surgery), and medication use via interviews by trained technicians or via self-administered questionnaires. The health examination included anthropometry, blood pressure, laboratory measurements, and ocular examinations. Of the 9,940 individuals who agreed to participate in the ocular investigations and who were aged over 40 years, we excluded those who had a diagnosis of glaucoma or any history of IOP-lowering treatment $(\mathrm{n}=490)$; a history of ocular laser treatment or surgery, including refractive or cataract surgeries, corneal oedema or dystrophy $(n=1,051)$; incomplete data on anthropometric or laboratory measurements $(n=1,022)$; or missing or outlying IOP measurements $(\mathrm{n}=591)$. Thus, 4,013 males and 2,773 females were finally enrolled in this study.

Written informed consent was obtained from all individuals. The institutional review boards at Osaka University, Osaka; National Cancer Center, Tokyo; Keio University, Tokyo; and the University of Tsukuba, Ibaraki approved the study. This study adhered to the tenets of the Declaration of Helsinki and the laws of Chikusei City with respect to maintaining the privacy of the participants.

Systemic examination and exposure assessment. Anthropometric parameters, including waist circumference, weight, and height, were measured by trained technicians during the study. The BMI was calculated as weight $(\mathrm{kg})$ divided by height $(\mathrm{m})$ squared. Blood pressure was taken on the right upper arm twice by trained technicians with the participant in the sitting position, and the mean value of these two successive readings was utilized in this study. Blood samples were collected for measurements of serum glucose (fasting or non-fasting), $\mathrm{HbAlc}$, and cholesterol concentrations. The fasting state was considered the state after a fasting duration of at least $10 \mathrm{~h}$ after the last meal. In 2017, serum glucose was excluded from the examination protocol. Hence, serum glucose data were available only from 2013-2016. Type 2 diabetes was defined as a self-reported history of physician-diagnosed diabetes, self-reported use of antidiabetic medication, or HbA1c levels $\geq 6.5 \%{ }^{62,63}$. In accordance with the current guidelines from the Committee of the Japan Diabetes Society on the Diagnostic Criteria of Diabetes Mellitus ${ }^{63}$, the cut-off points of $6.0 \%$ for HbAlc, as well as $<110$ and $<140 \mathrm{mg} / \mathrm{dL}$ for fasting and non-fasting serum glucose levels, respectively, were used.

Ocular examination and assessment of intraocular pressure. Standardised ocular examinations were performed by trained ophthalmologists. The IOP was determined by three successive readings of the right eye obtained by a non-contact tonometer (Tonoref ${ }^{\mathrm{TM}} \mathrm{II}$; Nidek Co., Ltd., Tokyo, Japan). Ocular hypertension was defined as a right-eye IOP $>21 \mathrm{mmHg}$ with no optic disc abnormalities, history of self-reported physician-diagnosed glaucoma, or use of any antiglaucoma therapy ${ }^{64}$. CCT was measured in the right eye using a specular-type pachymeter (Specular Microscope XIII; Konan, Nishinomiya, Japan). 
Statistical analysis. Age- and sex-adjusted mean values for continuous variables and proportions for categorical variables were compared according to the participants' diabetic status using regression analysis and logistic regression analysis, respectively. Analyses of covariance models were used to assess the relationships of mean IOP with diabetes, serum HbAlc, and serum glucose after adjusting for a priori known factors that affect IOP, including age (continuous), sex (male vs. female), smoking status (never, ex-smokers, or current smokers), alcohol intake ( $<23,23$ to $<46, \geq 46 \mathrm{~g} /$ day), hypertension (yes vs. no), and BMI ( $<25 \mathrm{vs.} \geq 25 \mathrm{~kg} / \mathrm{m}^{2}$ ) in the primary multivariable model. Because CCT may mediate the relationship between hyperglycaemia and IOP, we additionally adjusted for CCT in the secondary model.

Multivariable logistic regression models were used after controlling for the same sets of confounders as stated above to analyse the relationships between the prevalence of ocular hypertension and diabetes, serum HbA1c, and serum glucose. The adjusted ORs and 95\% CIs were calculated. All analyses were performed using SAS software (Version 9.4, SAS Institute, Cary, NC, USA). All P-values were two-sided, and a P-value of $<0.05$ was considered statistically significant.

\section{Data availability}

For information on how to submit an application for gaining access to JPHC-NEXT data and/or biospecimens, please follow the instructions at https://epi.ncc.go.jp/jphcnext/en/access/index.html.

Received: 23 October 2019; Accepted: 9 March 2020;

Published online: 24 March 2020

\section{References}

1. Chan, J. C. N. et al. Diabetes in Asia: Epidemiology, risk factors, and pathophysiology. JAMA 301, 2129-2140 (2009).

2. Malik, V. S., Willett, W. C. \& Hu, F. B. Global obesity: Trends, risk factors and policy implications. Nat. Rev. Endocrinol. 9, 13-27 (2013).

3. Bommer, C. et al. Global economic burden of diabetes in adults: Projections from 2015 to 2030. Diabetes Care 41, 963-970 (2018).

4. Dielemans, I. et al. Primary open-angle glaucoma, intraocular pressure, and diabetes mellitus in the general elderly population. The Rotterdam Study. Ophthalmology 103, 1271-1275 (1996).

5. Sahin, A., Bayer, A., Ozge, G. \& Mumcuoğlu, T. Corneal biomechanical changes in diabetes mellitus and their influence on intraocular pressure measurements. Invest. Ophthalmol. Vis. Sci. 50, 4597-4604 (2009).

6. Pimentel, L. G. M., Gracitelli, C. P. B., da Silva, L. S. C., Souza, A. K. S. \& Prata, T. S. Association between glucose levels and intraocular pressure: Pre- and postprandial analysis in diabetic and nondiabetic patients. J. Ophthalmol. 2015, 832058 (2015).

7. Mitchell, P., Smith, W., Chey, T. \& Healey, P. R. Open-angle glaucoma and diabetes: the Blue Mountains eye study, Australia. Ophthalmology 104, 712-718 (1997).

8. Tan, G. S., Wong, T. Y., Fong, C.-W. \& Aung, T. Diabetes, metabolic abnormalities, and glaucoma. Arch. Ophthalmol. 127, 1354-1361 (2009).

9. Zhao, D., Cho, J., Kim, M. H., Friedman, D. S. \& Guallar, E. Diabetes, fasting glucose, and the risk of glaucoma: a meta-analysis. Ophthalmology 122, 72-78 (2015).

10. Luo, X.-Y. et al. Direct and indirect associations between diabetes and intraocular pressure: The Singapore Epidemiology of Eye Diseases Study. Invest. Ophthalmol. Vis. Sci. 59, 2205-2211 (2018).

11. Quigley, H. A. \& Broman, A. T. The number of people with glaucoma worldwide in 2010 and 2020. Br. J. Ophthalmol. 90, 262-267 (2006).

12. Cavallerano, J. Ocular manifestations of diabetes mellitus. Optom. Clin. 2, 93-116 (1992).

13. Didenko, T. N., Smoliakova, G. P., Sorokin, E. L. \& Egorov, V. V. [Clinical and pathogenetic features of neurotrophic corneal disorders in diabetes]. Vestn. Oftalmol. 115, 7-11 (1999).

14. Hallberg, C. K., Trocme, S. D. \& Ansari, N. H. Acceleration of corneal wound healing in diabetic rats by the antioxidant Trolox. Res. Commun. Mol. Pathol. Pharmacol. 93, 3-12 (1996).

15. Kabosova, A. et al. Human diabetic corneas preserve wound healing, basement membrane, integrin and MMP-10 differences from normal corneas in organ culture. Exp. Eye Res. 77, 211-217 (2003).

16. Lee, J. S., Oum, B. S., Choi, H. Y., Lee, J. E. \& Cho, B. M. Differences in corneal thickness and corneal endothelium related to duration in diabetes. Eye (Lond.) 20, 315-318 (2006).

17. Rehany, U., Ishii, Y., Lahav, M. \& Rumelt, S. Ultrastructural changes in corneas of diabetic patients: an electron-microscopy study. Cornea 19, 534-538 (2000).

18. Shah, S. et al. Relationship between corneal thickness and measured intraocular pressure in a general ophthalmology clinic. Ophthalmology 106, 2154-2160 (1999).

19. Doughty, M. J. \& Zaman, M. L. Human corneal thickness and its impact on intraocular pressure measures: a review and metaanalysis approach. Surv. Ophthalmol. 44, 367-408 (2000).

20. Shah, S. Accurate intraocular pressure measurement-the myth of modern ophthalmology? Ophthalmology 107, 1805-1807 (2000).

21. Wu, S. Y. \& Leske, M. C. Associations with intraocular pressure in the Barbados Eye Study. Arch. Ophthalmol. 115, 1572-1576 (1997).

22. Son, J., Koh, H. \& Son, J. The association between intraocular pressure and different combination of metabolic syndrome components. BMC Ophthalmol. 16, 76 (2016).

23. Wu, C.-J. et al. Postprandial glucose as a risk factor for elevated intraocular pressure. PLoS One 11, e0168142 (2016).

24. Cohen, E., Kramer, M., Shochat, T., Goldberg, E. \& Krause, I. Relationship between serum glucose levels and intraocular pressure: A population-based cross-sectional study. J. Glaucoma 26, 652-656 (2017).

25. Coleman, A. L. \& Miglior, S. Risk factors for glaucoma onset and progression. Surv. Ophthalmol. 53, S3-S10 (2008).

26. Al Owaifeer, A. M. \& Al Taisan, A. A. The role of diet in glaucoma: A review of the current evidence. Ophthalmol. Ther. 7, 19-31 (2018).

27. Wang, Y. X., Xu, L., Wei, W. B. \& Jonas, J. B. Intraocular pressure and its normal range adjusted for ocular and systemic parameters. The Beijing Eye Study 2011. PLoS One 13, e0196926 (2018).

28. Foster, P. J. et al. Central corneal thickness and intraocular pressure in a Mongolian population. Ophthalmology 105, 969-973 (1998).

29. Kawase, K., Tomidokoro, A., Araie, M., Iwase, A. \& Yamamoto, T. Ocular and systemic factors related to intraocular pressure in Japanese adults: the Tajimi study. Br. J. Ophthalmol. 92, 1175-1179 (2008).

30. Shiose, Y. et al. Epidemiology of glaucoma in Japan-A nationwide glaucoma survey. Jpn. J. Ophthalmol. 35, 133-155 (1991).

31. Nomura, H., Shimokata, H., Ando, F., Miyake, Y. \& Kuzuya, F. Age-related changes in intraocular pressure in a large Japanese population: a cross-sectional and longitudinal study. Ophthalmology 106, 2016-2022 (1999). 
32. Iwase, A. et al. The prevalence of primary open-angle glaucoma in Japanese: The Tajimi Study. Ophthalmology 111, 1641-1648 (2004).

33. Yamamoto, S. et al. Primary open-angle glaucoma in a population associated with high prevalence of primary angle-closure glaucoma: The Kumejima Study. Ophthalmology 121, 1558-1565 (2014).

34. Sommer, A. et al. Relationship between intraocular pressure and primary open angle glaucoma among white and black Americans. The Baltimore Eye Survey. Arch. Ophthalmol. 109, 1090-1095 (1991).

35. Chua, J. et al. Ethnic differences of intraocular pressure and central corneal thickness: The Singapore Epidemiology of Eye Diseases study. Ophthalmology 121, 2013-2022 (2014).

36. Tielsch, J. M., Katz, J., Quigley, H. A., Javitt, J. C. \& Sommer, A. Diabetes, intraocular pressure, and primary open-angle glaucoma in the Baltimore Eye Survey. Ophthalmology 102, 48-53 (1995).

37. de Voogd, S. et al. Is diabetes mellitus a risk factor for open-angle glaucoma? The Rotterdam Study. Ophthalmology 113, 1827-1831 (2006).

38. Goldich, Y. et al. Effect of diabetes mellitus on biomechanical parameters of the cornea. J. Cataract Refract. Surg. 35, 715-719 (2009).

39. Shoshani, Y. et al. Impaired ocular blood flow regulation in patients with open-angle glaucoma and diabetes. Clin. Exp. Ophthalmol. 40, 697-705 (2012).

40. Oh, S. W., Lee, S., Park, C. \& Kim, D. J. Elevated intraocular pressure is associated with insulin resistance and metabolic syndrome. Diabetes Metab. Res. Rev. 21, 434-440 (2005).

41. Shepard, A. R. et al. Adenoviral gene transfer of active human transforming growth factor- $\beta 2$ elevates intraocular pressure and reduces outflow facility in rodent eyes. Invest. Ophthalmol. Vis. Sci. 51, 2067-2076 (2010).

42. Wordinger, R. J. et al. Cultured human trabecular meshwork cells express functional growth factor receptors. Invest. Ophthalmol. Vis. Sci. 39, 1575-1589 (1998)

43. Gottanka, J., Chan, D., Eichhorn, M., Lütjen-Drecoll, E. \& Ethier, C. R. Effects of TGF- $\beta 2$ in perfused human eyes. Invest. Ophthalmol. Vis. Sci. 45, 153-158 (2004).

44. Fleenor, D. L. et al. TGF32-induced changes in human trabecular meshwork: implications for intraocular pressure. Invest. Ophthalmol. Vis. Sci. 47, 226-234 (2006).

45. Ochiai, Y. \& Ochiai, H. Higher concentration of transforming growth factor- $\beta$ in aqueous humor of glaucomatous eyes and diabetic eyes. Jpn. J. Ophthalmol. 46, 249-253 (2002).

46. Min, S. H., Lee, T.-I., Chung, Y. S. \& Kim, H. K. Transforming growth factor- $\beta$ levels in human aqueous humor of glaucomatous, diabetic and uveitic eyes. Korean J. Ophthalmol. 20, 162-165 (2006)

47. Park, C. H. \& Kim, J. W. Effect of advanced glycation end products on oxidative stress and senescence of trabecular meshwork cells. Korean J. Ophthalmol. 26, 123-131 (2012).

48. Schmidt, A. M. et al. Cellular receptors for advanced glycation end products. Implications for induction of oxidant stress and cellular dysfunction in the pathogenesis of vascular lesions. Arterioscler. Thromb. 14, 1521-1528 (1994).

49. Ramasamy, R. et al. Advanced glycation end products and RAGE: a common thread in aging, diabetes, neurodegeneration, and inflammation. Glycobiology 15, 16R-28R (2005).

50. Tektas, O.-Y. \& Lütjen-Drecoll, E. Structural changes of the trabecular meshwork in different kinds of glaucoma. Exp. Eye Res. 88, 769-775 (2009).

51. Janićijević-Petrović, M. A. et al. Evaluation of central corneal thickness in patients with ocular hypertension and primary open-angle glaucoma. Med. Glas. (Zenica). 11, 115-119 (2014).

52. Wei, W. et al. Correlation analysis between central corneal thickness and intraocular pressure in juveniles in Northern China: The Jinan City eye study. PLoS One 9, e104842 (2014).

53. Choo, M. et al. Corneal changes in type II diabetes mellitus in Malaysia. Int. J. Ophthalmol. 3, 234-236 (2010).

54. Su, D. H. W. et al. Diabetes, hyperglycemia, and central corneal thickness: the Singapore Malay Eye Study. Ophthalmology 115, 964-968.e1 (2008).

55. Baron, R. M. \& Kenny, D. A. The moderator-mediator variable distinction in social psychological research: conceptual, strategic, and statistical considerations. J. Pers. Soc. Psychol. 51, 1173-1182 (1986).

56. MacKinnon, D. P., Fairchild, A. J. \& Fritz, M. S. Mediation analysis. Annu. Rev. Psychol. 58, 593-614 (2007).

57. Shiga, Y. et al. Genome-wide association study identifies seven novel susceptibility loci for primary open-angle glaucoma. Hum. Mol. Genet. 27, 1486-1496 (2018).

58. Kanai, M. et al. Genetic analysis of quantitative traits in the Japanese population links cell types to complex human diseases. Nat. Genet. 50, 390-400 (2018).

59. Laville, V. et al. Genetic correlations between diabetes and glaucoma: An analysis of continuous and dichotomous phenotypes. Am. J. Ophthalmol. 206, 245-255 (2019).

60. Burr, J. M. et al. Surveillance for ocular hypertension: An evidence synthesis and economic evaluation. Health Technol. Assess. 16, $1-271(2012)$

61. Sawada, N. et al. The Japan Public Health Center-based Prospective Study for the Next Generation (JPHC-NEXT): Study design and participants. J. Epidemiol. 30, 46-54 (2019).

62. Alberti, K. G. \& Zimmet, P. Z. Definition, diagnosis and classification of diabetes mellitus and its complications. Part 1: diagnosis and classification of diabetes mellitus provisional report of a WHO consultation. Diabet. Med. 15, 539-553 (1998).

63. Seino, Y. et al. Report of the expert committee on the classification and diagnostic criteria of diabetes mellitus. J. Diabetes Investig. 1, $212-228(2010)$

64. Tielsch, J. M., Katz, J., Sommer, A., Quigley, H. A. \& Javitt, J. C. Hypertension, perfusion pressure, and primary open-angle glaucoma. A population-based assessment. Arch. Ophthalmol. 113, 216-221 (1995).

\section{Acknowledgements}

We would like to thank the participants and staff of the Japan Public Health Center-based Prospective Study for the Next Generation (JPHC-NEXT) protocol for their valuable contributions. The authors assume full responsibility for analyses and interpretation of these data. This work was supported by the National Cancer Centre Research and Development Fund (since 2011) and a Grant-in-Aid for Cancer Research from the Ministry of Health, Labour and Welfare of Japan (from 1989 to 2010) and JSPS KAKENHI grant [JP16K11271 to K.Yu.]. K.Yu. was also supported by a 2015 Novartis Research Grant.

\section{Author contributions}

Design of the study: A.H. and N.S.; Study conduct: A.H.; Collection, management, analysis, and interpretation of the data: A.H., N.S., K.Yu., M.U., Y.O., M.S., K.Ya., H.I., K.T. and S.T.; and Preparation, review and final approval of the manuscript: A.H., N.S., K.Yu., M.U., Y.O., M.S., K.Ya., H.I., K.T. and S.T. All authors reviewed the manuscript and approved the final version. 


\section{Competing interests}

The authors declare no competing interests.

\section{Additional information}

Supplementary information is available for this paper at https://doi.org/10.1038/s41598-020-62135-3.

Correspondence and requests for materials should be addressed to N.S. or Kenya Yuki

Reprints and permissions information is available at www.nature.com/reprints.

Publisher's note Springer Nature remains neutral with regard to jurisdictional claims in published maps and institutional affiliations.

(c) (i) Open Access This article is licensed under a Creative Commons Attribution 4.0 International License, which permits use, sharing, adaptation, distribution and reproduction in any medium or format, as long as you give appropriate credit to the original author(s) and the source, provide a link to the Creative Commons license, and indicate if changes were made. The images or other third party material in this article are included in the article's Creative Commons license, unless indicated otherwise in a credit line to the material. If material is not included in the article's Creative Commons license and your intended use is not permitted by statutory regulation or exceeds the permitted use, you will need to obtain permission directly from the copyright holder. To view a copy of this license, visit http://creativecommons.org/licenses/by/4.0/.

(C) The Author(s) 2020 